\title{
Feasibility of Gastrointestinal Endoscopy Training in Surgery Residency at a Public Referal Hospital in Malawi
}

\author{
Gift Mulima' $^{1}$, Chifundo Kajombo', Mark Hendrickse ${ }^{2}$ \\ ${ }^{1}$ Kamuzu Central Hospital, Lilongwe, Malawi \\ ${ }^{2}$ Blackpool Teaching Hospitals, Blackpool, England \\ Email: gmulima@gmail.com
}

How to cite this paper: Mulima, G., Kajombo, C. and Hendrickse, M. (2017) Feasibility of Gastrointestinal Endoscopy Training in Surgery Residency at a Public Referal Hospital in Malawi. Journal of Biosciences and Medicines, 5, 35-41. https://doi.org/10.4236/jbm.2017.54004

Received: February 15, 2017

Accepted: April 25, 2017

Published: April 30, 2017

Copyright $\odot 2017$ by authors and Scientific Research Publishing Inc. This work is licensed under the Creative Commons Attribution International License (CC BY 4.0).

http://creativecommons.org/licenses/by/4.0/

\begin{abstract}
Objective: We set out to explore the impact of gastrointestinal (GI) endoscopy training on the surgery residency program at Kamuzu Central Hospital $(\mathrm{KCH})$, Lilongwe, Malawi. Methods: We reviewed the hospital and published data regarding GI endoscopy and the surgical training at $\mathrm{KCH}$ from 2009 to 2015. The endoscopy database was reviewed determining endoscopic procedures done during the same period. Results: Since the onset of surgical residency program at $\mathrm{KCH}$ in 2009, 7 residents (5 now COSECSA Fellows) have been trained as independent GI endoscopists with support from the British Society of Gastroenterology andLiverpool Malawi Wellcome trust. Between them, with supervision, 1304 upper and 28 lower GI scopes have been done; $22 \%$ therapeutic. Endoscopy capacity has improved from an average of 12 patients per week to about 30 patients per week with a well-developed oesophageal variceal banding and tumour stenting capacity. Weekly endoscopy training lists by the fellows have also been established. During the same time period, 3 papers have been published from the endoscopy data with the residents as principle investigators or co-authors. Conclusion: With dedicated support endoscopy training during surgical residency is feasible in resource poor settings and improves diagnostic capacity for better patient care ultimately benefiting trainees in gaining endoscopy diagnostic and therapeutic skills, appreciating disease spectrum and management, and exposure to research skills.
\end{abstract}

\section{Keywords}

Endoscopy, Surgery, Training, Residency, Kamuzu

\section{Introduction}

Kamuzu central hospital $(\mathrm{KCH})$ is one of four major and tertiary public referral 
hospitals in Malawi and the only one in the central region of the country. It has a bed capacity of 1200 and serving a population of approximately 6.3 million Malawians [1]. In view of a high surgical disease burden at $\mathrm{KCH}$ and the country as a whole and deficiency of well qualified surgeons, a surgery training program (STP) was established at the institution in July 2009 after accreditation by the College of Surgeons of East Southern and Central Africa (COSECSA) [2]. Since its inception, 5 individuals have attained the fellowship qualification (4 general surgeons, 2 orthopaedic surgeons and 1 paediatric surgeon).

Gastrointestinal (GI) conditions contribute a huge proportion of general surgical practice at $\mathrm{KCH}$. Published data indicate that an average of 993 laparotomies per year due to GI related conditions were done from 2007 to 2010 at the institution [3]. Additionally, looking at gastrointestinal endoscopy (GE) practice at $\mathrm{KCH}$, Lindsay Wolf has described the spectrum of disease among patients with GI symptoms. Dysphagia (37\%), haematemesis (21\%), and epigastric pain (16\%) are the most common indications for endoscopy whilst oesophageal cancer (27\%) and oesophageal varices (17\%) are the common diagnoses [4]. This clearly means that the importance for $\mathrm{GE}$ at $\mathrm{KCH}$ does not need to be overemphasized.

As is the case with surgery, GE is a complex task that involves an interaction of cognitive and manual skills [5] such that GE training may presumably be integrated in a STP without major challenges. Unfortunately in reality, time constraints during surgery residency hinder a smooth GE training program. In United Kingdom, high rates of dissatisfaction with endoscopy training have been observed among surgical trainees nationally. Reasons stated include no scheduled training lists, conflicting elective/emergency commitments and competition and absence of training lists [6].

Before the residency program, one or two foreign surgeons were available for mainly diagnostic GE due to limited therapeutic resources. Two dedicated weekly endoscopy lists with a maximum of 12 patients per week were being done. Taking advantage of the STP, with support from the British Society of Gastroenterology (BSG) and Liverpool Malawi Well come Trust (LMW), a GE training program started in 2012 at $\mathrm{KCH}$, with basic endoscopy skills training followed by skills enhancement and advanced (therapeutic) endoscopy skills at designated intervals. During all this period, surgery residents were under supervision from the experienced surgeons at $\mathrm{KCH}$ and regular visits by gastroenterologists from Black Pool and Glasgow in the UK, with personal resources and support from the BSG.

Since the endoscopy training started at the institution, its impact on the STP and possible challenges have not been evaluated before hence our interest to carry out this study.

\section{Methods}

\subsection{Place of Study}

The study was conducted at $\mathrm{KCH}$, Lilongwe, Malawi. 


\subsection{Data Collection and Analysis}

We reviewed KCH GE and STP related published data and hospital records from 2009 to 2015. The data from published records was obtained from an exhaustive internet search for all articles relating to the training programs at $\mathrm{KCH}$. The Hospital records reviewed included a Microsoft access GE database in the hospital's endoscopy unit and documents/records of trainee recruitment program in the department of Surgery. Published data in which residents were involved as authors was particularly noted. Data abstracted from hospital records included number of residents recruited in the STP and number of residents trained in GET. Here was no special criteria for inclusion of residents in the GE training as opportunity to train in GE was offered to all trainees in the STP Records regarding supportive and supervisory visits by members of the BSG and LMW were also reviewed. In addition, the $\mathrm{KCH}$ endoscopy unit data base was reviewed to determine the scope of endoscopic procedures done during the same period. These procedures were categorized into diagnostic; lesion identification with/out biopsy and therapeutic procedures; with curative or palliative intent.

\subsection{Ethical Consideration}

In our study, no patient and surgical resident identifiers were used therefore ethical approval was not necessary. However, authorization to access hospital records including the endoscopy database was sought from the $\mathrm{KCH}$ hospital administration.

\section{Results}

Since the onset of the STP, 17 residents have been recruited in the program, with two residents training in orthopedics and 15 in general surgery. 53\% $(n=8)$ of the general surgery residents have been trained in GE (Table 1).

During the course of the endoscopy training program within the STP, supervisory and supportive visits by well qualified gastroenterologists were done (Table 2). These visits were supported by the British council, British society of gastroenterology (BSG), Mersey school of endoscopy (MSE) and the Malawi Liverpool welcome trust (MLW).

A total of 1304 upper and 28 lower GEs were done from 2012 to 2015 in which at least one surgery resident was involved. 14 were colonoscopies and 14 sigmoidoscopies. The common findings are as shown in Figure 1.

Among the upper GE procedures, 22\% $(\mathrm{n}=285)$ therapeutic endoscopic procedures have been done (Figure 2).

Since onset of the STP and GET, three GE related papers have been published with residents as first authors or co-authors (Table 3).

\section{Discussion}

The future of surgical training in Africa depends on the availability of the leadership to recruit and attract trainees and trainers, adopt innovative educational 
technologies and growth of demand for quality surgical care [7]. In Malawi, particularly $\mathrm{KCH}$, the STP is young but has afforded to recruit and retain most of the trainees despite obvious resource capacity limitations (Table 1).

Among other institutions in the country with STPs, GE training has been firmly established and incorporated in the STP at $\mathrm{KCH}$ only. Through links with the Mersey school of Endoscopy and the Liverpool Malawi Welcome trust and financial support from the British council and BSG, a number of supportive and supervisory visits to $\mathrm{KCH}$ endoscopy unit have been made since 2011. These visits included provision of basic skills course for those with no or very limited endoscopy experience, refresher/enhanced skills course for those with endoscopy experience (Table 2) [8]. Milestones gained through the GE training are appreciable due to sustained skill impartation (Table 2), endoscopy equipment and supplies provision mainly from the STP sponsorship-University of Belgen, Norway, University of North Carolina (UNC), USA and BSG/Blackpool hospital in UK.

Surgical training programs elsewhere struggle with the integration of similar training into their curriculum given the constraints of time and trainee responsibilities and expectations [9]. There is no consensus on the optimal way to teach endoscopy [5]. Our model has seemed to produce conspicuous results that point towards feasibility of GE training incorporation in the training program (STP).

Table 1. STP and GE resident recruitment.

\begin{tabular}{cc}
\hline Parameter & Number \\
Residents recruited since 2009 & 17 \\
Residents graduated to FCS level and have received endoscopy training & 5 \\
Residents who received endoscopy training and currently in surgery training & 3 \\
Residents currently in training & 3 \\
Surgeons supervising Endoscopy training at $\mathrm{KCH}$ & 6 \\
\hline
\end{tabular}

Table 2. Summary of GE training supportive visits

\begin{tabular}{cccccc}
\hline Year & Level of training & $\begin{array}{c}\text { Local } \\
\text { faculty }\end{array}$ & $\begin{array}{c}\text { International } \\
\text { faculty }\end{array}$ & $\begin{array}{c}\text { Trainee } \\
\text { participants }\end{array}$ & $\begin{array}{c}\text { Supporting } \\
\text { Institution }\end{array}$ \\
\hline 2011 & $\begin{array}{c}\text { Basic skills course } \\
\text { Refresher Basic skills } \\
\text { course }\end{array}$ & 3 & 3 & 6 & $\begin{array}{c}\text { British } \\
\text { council \& } \\
\text { BSG }\end{array}$ \\
2012 & Basic skills course & 4 & 2 & 2 & MSE \& \\
& Enhanced skills course & & & 2 & MLW \\
& Basic skills course & & 1 & 3 & BSG,MLW \\
$2013 \quad$ Enhanced skills course & TGT & & 3 & 3 & \\
& Basic skills course & 4 & 3 & 1 & BSG \\
\hline
\end{tabular}


Strictly speaking, the GE training is not mandatory at $\mathrm{KCH}$ nor it is in the COSECSA curriculum perhaps due to resource limitations. Given the benefits we have seen i.e. surgical trainees gaining diagnostic and therapeutic GE skills (Figure 1 and Figure 2), appreciating and managing endoscopically and probably surgically-those recommended for surgery, common GI pathologies seen in their practice, well designed GE trainings should be considered in every STP especially in Africa where demand for endoscopy is high and capacity for endoscopy is limited in many places [10]. Resource constraints restrict widespread use of endoscopy both for diagnostic and therapeutic procedures in many African countries such that very few physicians in Africa have acquired skills in endoscopy [11]. It is common knowledge now that COSECSA is producing more surgeons every year and could be a prime vehicle to promote GE training and service in the region and beyond.GE resource mobilization is crucial in that regard.

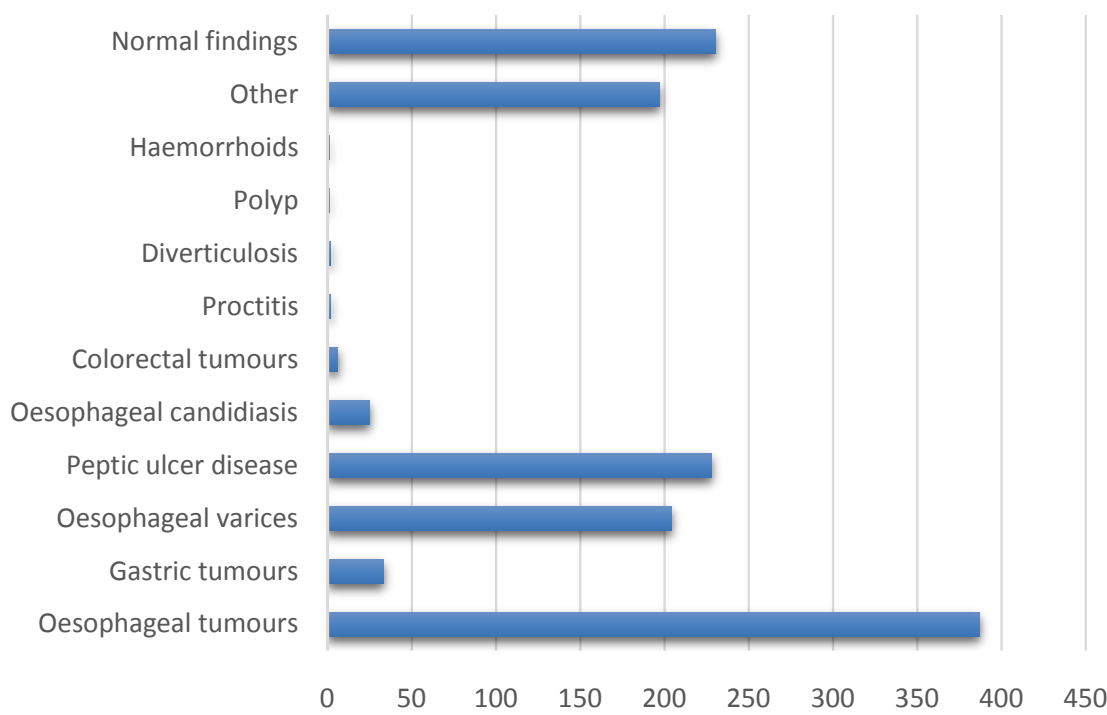

Figure 1. Endoscopic findings among patients attending GE $(n=1332)$.

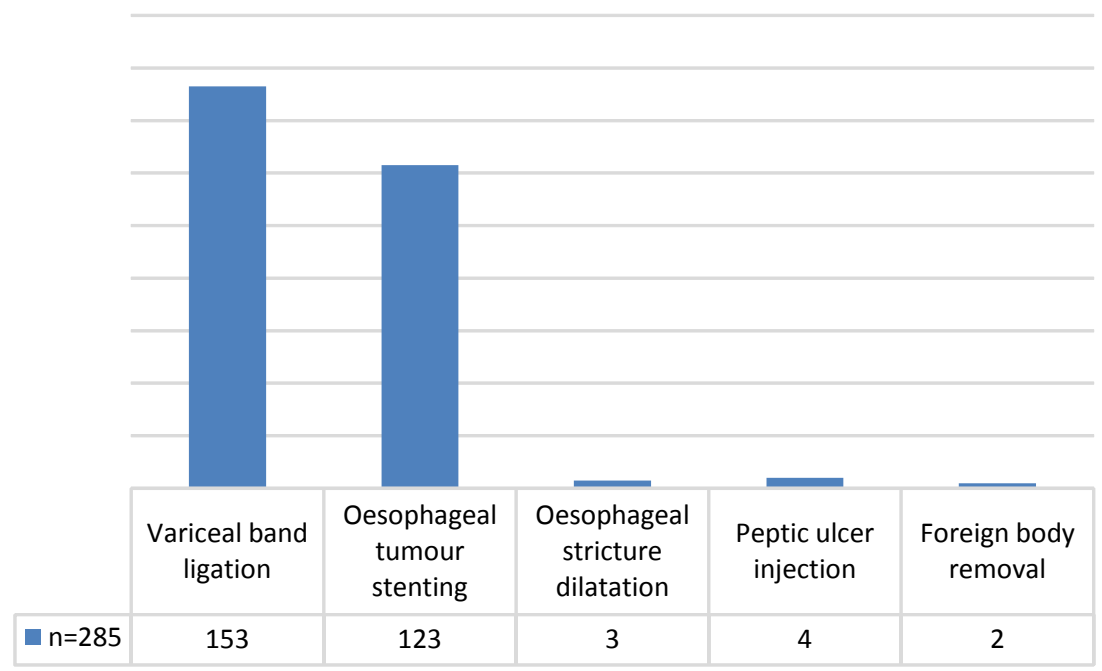

Figure 2. Therapeutic endoscopic procedures done at $\mathrm{KCH}(\mathrm{n}=285)$. 
Table 3. KCH Gastrointestinal Endoscopy related publications.

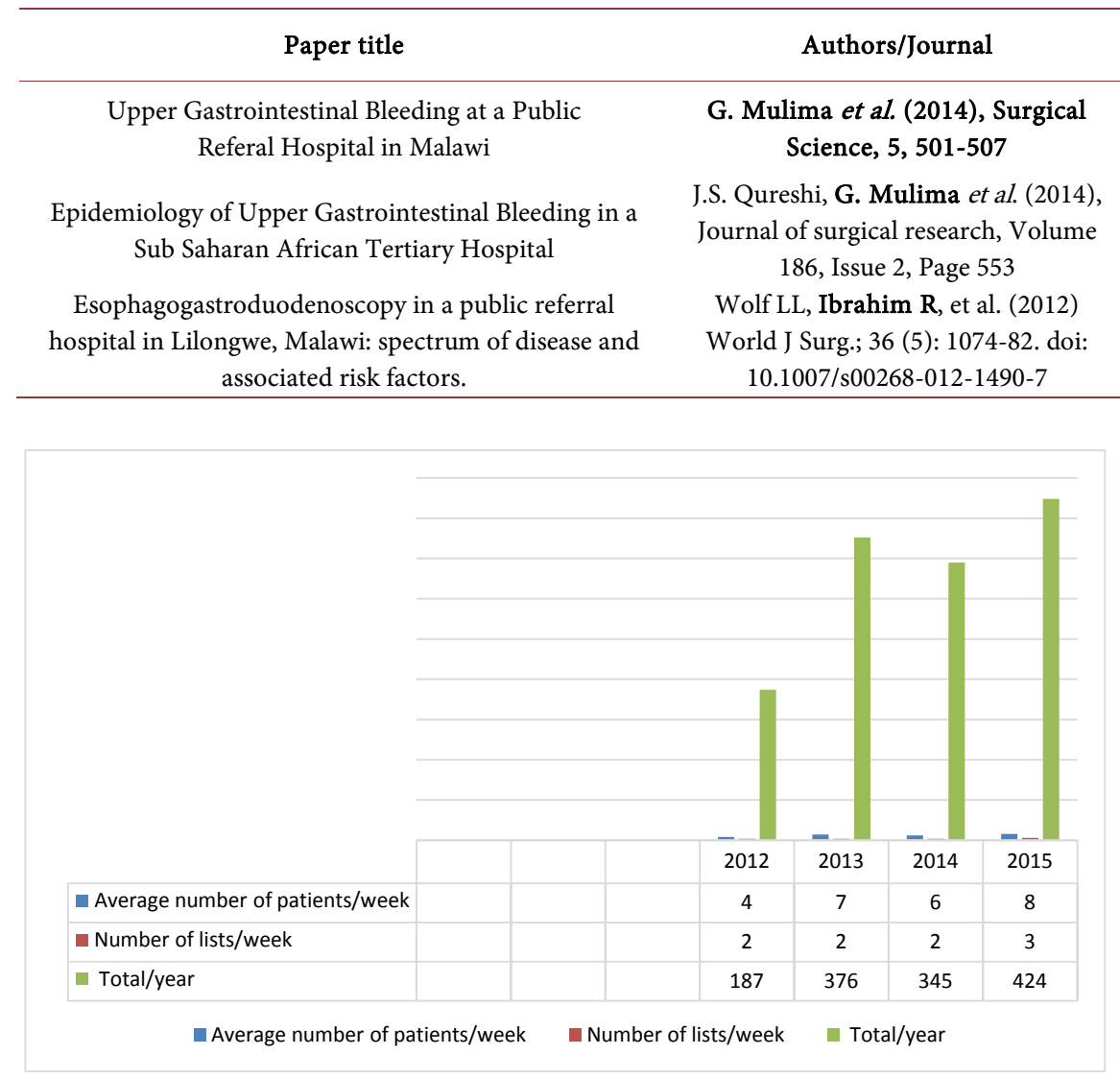

Figure 3. Progress of capacity for endoscopy at $\mathrm{KCH}$.

In sub-Saharan Africa, despite some efforts, research capacity and output remain low [7]. STPs in Africa can be ideal propellants of research and investment towards such a cause is worthwhile. Since the STP and GE training started at $\mathrm{KCH}$ in 2009 and 2011 respectively trainees have also written three endoscopy related papers (Table 3 ). This exemplifies the fact that given a well-established endoscopy practice in a surgery residency program, opportunities for research skills for trainees can be created.

Owing to the GE training program, the capacity for endoscopy at $\mathrm{KCH}$ has progressively improved (Figure 3). Obviously this eventually positively impacts on the surgical training and capacity at the institution. It is beyond the scope of this paper to ascertain accuracy in diagnostic capability among the trained residents and we recommend a well-designed prospective study to that effect.

\section{Conclusion}

With dedicated support gastrointestinal endoscopy training during surgical residency is feasible in resource poor settings and improves diagnostic capacity for better patient care ultimately benefiting trainees in gaining endoscopy diagnostic and therapeutic skills, appreciating disease spectrum and management, and exposure to research skills. 


\section{References}

[1] Malawi Population Data Sheet 2012.

[2] http://ameca.org.uk/directory/listing/kamuzu-central-hospital-malawi

[3] Qureshi, J.S., et al. (2013) Addressing Malawi’s Surgical Workforce Crisis: A Sustainable Paradigm for Training and Collaboration in Africa. Surgery, 153, 272-281. https://doi.org/10.1016/j.surg.2012.08.004

[4] Wolf, L.L., Ibrahim, R., Miao, C., Muyco, A., Hosseinipour, M.C. and Shores, C. (2012) Esophagogastroduodenoscopy in a Public Referral Hospital in Lilongwe, Malawi: Spectrum of Disease and Associated Risk Factors. World Journal of Surgery, 36, 1074-1082. https://doi.org/10.1007/s00268-012-1490-7

[5] Cooper, M.A. (2014) Surgical Residents' Perceptions on Learning Gastrointestinal Endoscopy: More Hours and More Standardization Wanted. Journal of Surgical Education, 71, 899-905. https://doi.org/10.1016/j.jsurg.2014.05.016

[6] Hammond, J.S., Watson, N.F.S., Lund, J.N. and Barton, J.R. (2013) Surgical Endoscopy Training: The Joint Advisory Group on Gastrointestinal Endoscopy National review. Frontline Gastroenterology, 4, 20-24. https://doi.org/10.1136/flgastro-2012-100242

[7] Galukande, M., et al. (2013) Challenges Facing Surgical Training in the Great Lakes Region in Sub-Saharan Africa: A Review Article. East and Central African Journal of Surgery, 18, 3-11.

[8] Hendrickse, M. (2013) BSG Sponsored Endoscopy Training at Kamazu Central Hospital-Malawi. http://www.bsg.org.uk/international

[9] Chang, L., Petros, J., Hess, D.T., et al. (2007) Integrating Simulation into a Surgical Residency Program: Is Voluntary Participation Effective? Surgical Endoscopy, 21, 418-421. https://doi.org/10.1007/s00464-006-9051-5

[10] Perl, D., Desmond Leddin, D, Bizos, D., et al. (2016) Endoscopic Capacity in West Africa. African Health Sciences, 16, 329. https://doi.org/10.4314/ahs.v16i1.44

[11] Lapido, O.A., Adekunle, A.O. and Akande, E.O. (2016) Gynaecologic Endoscopy and Experience with Training in Africa. Geneva Foundation for Medical Education and Research. http://www.gfmer.ch/Books/Endoscopy_book/Ch22b_Africa.html

Submit or recommend next manuscript to SCIRP and we will provide best service for you:

Accepting pre-submission inquiries through Email, Facebook, LinkedIn, Twitter, etc. A wide selection of journals (inclusive of 9 subjects, more than 200 journals)

Providing 24-hour high-quality service

User-friendly online submission system

Fair and swift peer-review system

Efficient typesetting and proofreading procedure

Display of the result of downloads and visits, as well as the number of cited articles

Maximum dissemination of your research work

Submit your manuscript at: http://papersubmission.scirp.org/

Or contact jbm@scirp.org 